\title{
The Innovation of Personnel Training Mode of Digital Media in China
}

\author{
Jiaogang Lin \\ Shandong Xiehe University, Shandong, 250107, China
}

Keywords: new media era; media talents; training mode

\begin{abstract}
In the rapid development of new media in China, the traditional media gradually formed the media technologies of different media, as well as the characteristics of focused communication and more obvious information interaction characteristics. These characteristics are also in the new media industry. The professional qualifications of media professionals have put forward higher requirements. Therefore, it is necessary to further promote the training mode suitable for the development of media talents and establish a practical and effective strategy to enhance the quality of media talents in order to more fully enhance the quality of media talents and make more contributions to the development of new media technologies.
\end{abstract}

\section{Introduction}

In the continuous development of China's media industry, there are different characteristics in different periods. The training of media talents has also experienced different stages such as oral communication, dissemination of printed textbooks, and broadcast and television broadcasting. These stages can also be called the period of traditional media personnel training.

\section{The main features of the new media era}

At present, the overall economy of our country has been developing steadily, the level of science and technology is also constantly improving, and the technological means of dissemination is gradually going deeper. Different channels of communication represented by broadcasting, film and television, and the Internet are gradually infiltrating between people's daily lives and work, and have a greater impact on people's lives. At present, China is in the era of new media development where multiple media concurrently exist. The traditional media industry is still the mainstream. However, through the research on relevant communication technologies in the new media era, the author finds that the era of new media has the following characteristics:

\subsection{The new media era has formed a pattern of heterogeneous media integration}

The era of new media is different from the traditional media era. It focuses more on the use of digital technology and the use of new media. At the same time, some traditional means, such as newspapers and television, are also integrated with new media technologies. As a result, the new 
media technology gradually shows the characteristics of panoramic and three-dimensional development, so that information has a more intuitive development space.

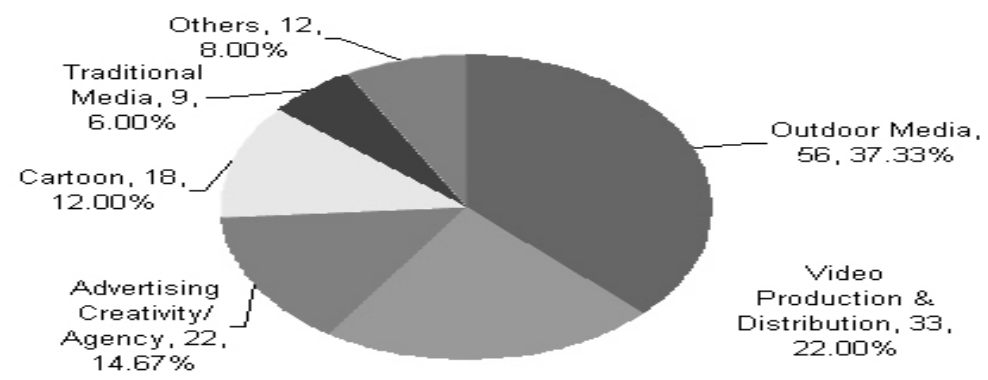

Fig. 1 Trends of Digital Media Industry in Recent Years

\subsection{Mass Communication to Focus Communication}

In general, information dissemination in the new media era will gradually shift from the blindness and non-classification of traditional media to the specific targeting of different consumers' needs, making the audience more concentrated. New media technology will have richer network video technology and programs after the technological transformation and development, and its classification will be more detailed. For each of the different details of classification is also more obvious, news, people's livelihood and other sections of different content to broadcast independently, so that the level of cultural resources can be the maximum degree of dissemination and development.

\subsection{The speed of change of information becomes faster}

The speed of the replacement of information is accelerating, and the important characteristics affecting the importance of information are the shortening of timeliness and the speed of its dissemination. On the other hand, TV stations should pay attention to the local news as an important content for coverage of new media transmission, which can enhance the program's interaction and ratings, for advertising revenue and the development of broadcasting and TV business have a certain degree of promotion.

\subsection{The information capacity is bigger and spreads more widely}

Because of the continuous development of China's digital network technology, the spread of traditional information is no longer limited by the overall capacity, and can further realize the "cloud sharing" feature on the network.

\section{Requirements of media talents in the era of new media}

Compared with the traditional media age, the era of new media not only has new features in its means and means of dissemination, but also has a significant change in the workforce of media professionals in the era of new media. From the current China's new media era for the quality of media talent demand, we believe that the quality requirements for film and television media talents should be carried out from the following aspects:

\subsection{The era of new media will pay more attention to the media literacy of media talents}

Judging from the overall laws of the media industry, no matter how fast the media's science and 
technology develop, the quality education of the media is still an important area for the media industry. This is necessary for every practitioner in the media. As a practical employee of the media industry, the literacy of the media also constantly requires its core values and spiritual recognition.

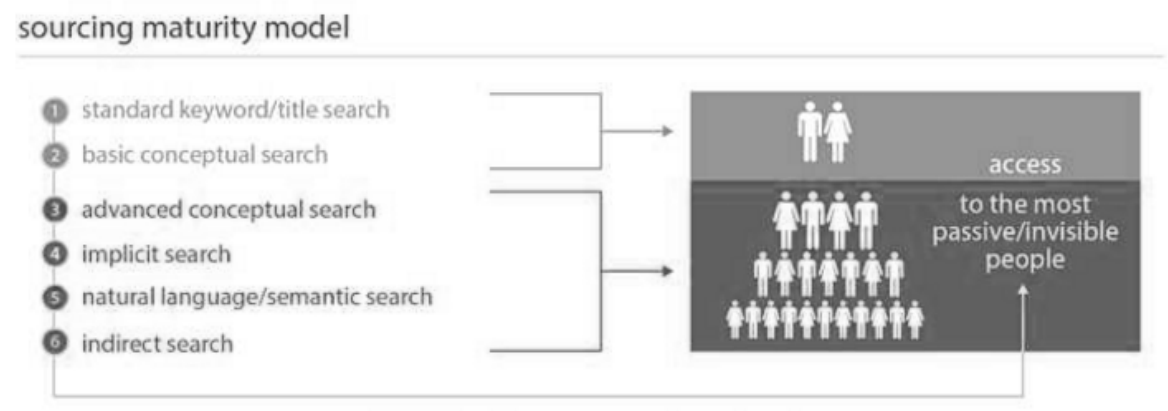

Fig.2 Digital Talent Development Model

\subsection{The era of new media requires the diversification of the quality of the media industry practitioners}

Due to the different integration characteristics among different media in the new media era in China, these characteristics further lead to the comprehensive quality of employees. Here we take the news gathering industry as an example, the quality of the practitioners of news needs to have more comprehensive and specific requirements. Under the premise of the preservation of the traditional media, the infiltration of multi-faceted emerging media has allowed journalists to face multimedia technology platforms and continue to develop new skills and qualities to meet the diverse needs of the audience.

\subsection{The era of new media requires media industry practitioners to have a clearer professionalism}

In the context of the new media's technological age, the communication between the audience and the communication personnel is constantly being strengthened. At the same time, the increase in the amount of information will also enhance the capabilities of employees. The economic benefits of developing and using digital media talents $(\mathrm{J})$ is equal to the digital media interaction coefficient $(\alpha)$ multiplied by the advance time (T) multiplied by the economic benefit (S) created per unit time, and then subtracted the cost (C).

$$
\mathrm{J}=\alpha \mathrm{TS}-\mathrm{C}
$$

\subsection{The era of new media requires media industry professionals to have stronger creative qualities}

Compared with the traditional characteristics of media communication, relevant practitioners in the new media era should have more innovative qualities. This is further evidenced by more news media personnel actively leaving the company. At present, different media are competing and more opportunities for innovation have to be transformed. These are difficult to imagine in the past in the traditional media era. Therefore, the traditional media industry needs to develop and innovate, and based on technological innovation, the overall strength of industrial talents is promoted, so that talents can participate in industry innovation and gradually improve the industry's level of innovation. 


\section{Adapt to the culltivation of media talents in the era of new media}

As far as the training of media talents in China is concerned, there are still many inadequacies in the training model, which is mainly reflected in the following aspects:

\subsection{The basic employability needs to be improved}

The people in the traditional media industry are relatively dominant in their basic professional abilities and have a greater proficiency in the expression of texts and the acquisition of information. However, these personnel are often unable to become familiar with emerging media technologies. The use of new types of communication tools also requires a long period of comprehensive adaptation. On the contrary, under the emerging media technology, practitioners are very familiar with emerging communication tools, but they lack some basic qualities in media literacy and written expression.

\subsection{Respond to media literacy needs to improve}

In the course of the development of the traditional media industry, the era characteristics of the corresponding media literacy often have insufficient adaptive characteristics. Because of the lack of traditional professional technical training, the new media environment is still unable to meet the needs of the media. In addition, because the technical talents of traditional media are under a relatively large working pressure, their attention to the quality of innovation and their ability to focus on cross-cutting, and the overall sense of innovation of personnel needs to be improved.

\section{Summary}

In the continuous development of China's media industry, there are different characteristics in different periods. The cultivation of media talents has also experienced different stages such as oral communication, dissemination of printed textbooks, and broadcast and television broadcasting. The different characteristics of these different stages also impose higher requirements on the quality of media professionals in the new media industry. Therefore, it is necessary to further promote the training mode suitable for the development of media talents and establish a practical and effective strategy to enhance the quality of media talents in order to more fully enhance the quality of media talents and make more contributions to the development of new media technologies.

\section{References}

[1] Xiao-Yun M A, Chai Y C. The Innovation of Student Management under the Reform of the College Personnel Training Mode[J]. Journal of Shaanxi Administration School, 2008.

[2] Song L L, Management S O, University H N. Study on Personnel Training Mode Transformation of Cultural Industry in China Under the Background of Technology Innovation[J]. Heilongjiang Researches on Higher Education, 2016.

[3] Zhou J, Qinglan F U, Haizhou L I. Innovation and achievenment of practice about vocational rehabilitation personnel training mode[J]. Zhejiang Medical Education, 2012. 